This item was submitted to Loughborough's Research Repository by the author.

Items in Figshare are protected by copyright, with all rights reserved, unless otherwise indicated.

\title{
Production of food-grade multiple emulsions with high encapsulation yield using oscillating membrane emulsification
}

PLEASE CITE THE PUBLISHED VERSION

http://dx.doi.org/10.1016/j.colsurfa.2014.05.011

PUBLISHER

(C) Elsevier B.V.

VERSION

AM (Accepted Manuscript)

LICENCE

CC BY-NC-ND 4.0

\section{REPOSITORY RECORD}

Vladisavljevic, Goran T., Bing Wang, Marijana M. Dragosavac, and R.G. Holdich. 2014. "Production of Foodgrade Multiple Emulsions with High Encapsulation Yield Using Oscillating Membrane Emulsification”. figshare. https://hdl.handle.net/2134/14658. 
This item was submitted to Loughborough's Institutional Repository (https://dspace.lboro.ac.uk/) by the author and is made available under the following Creative Commons Licence conditions.

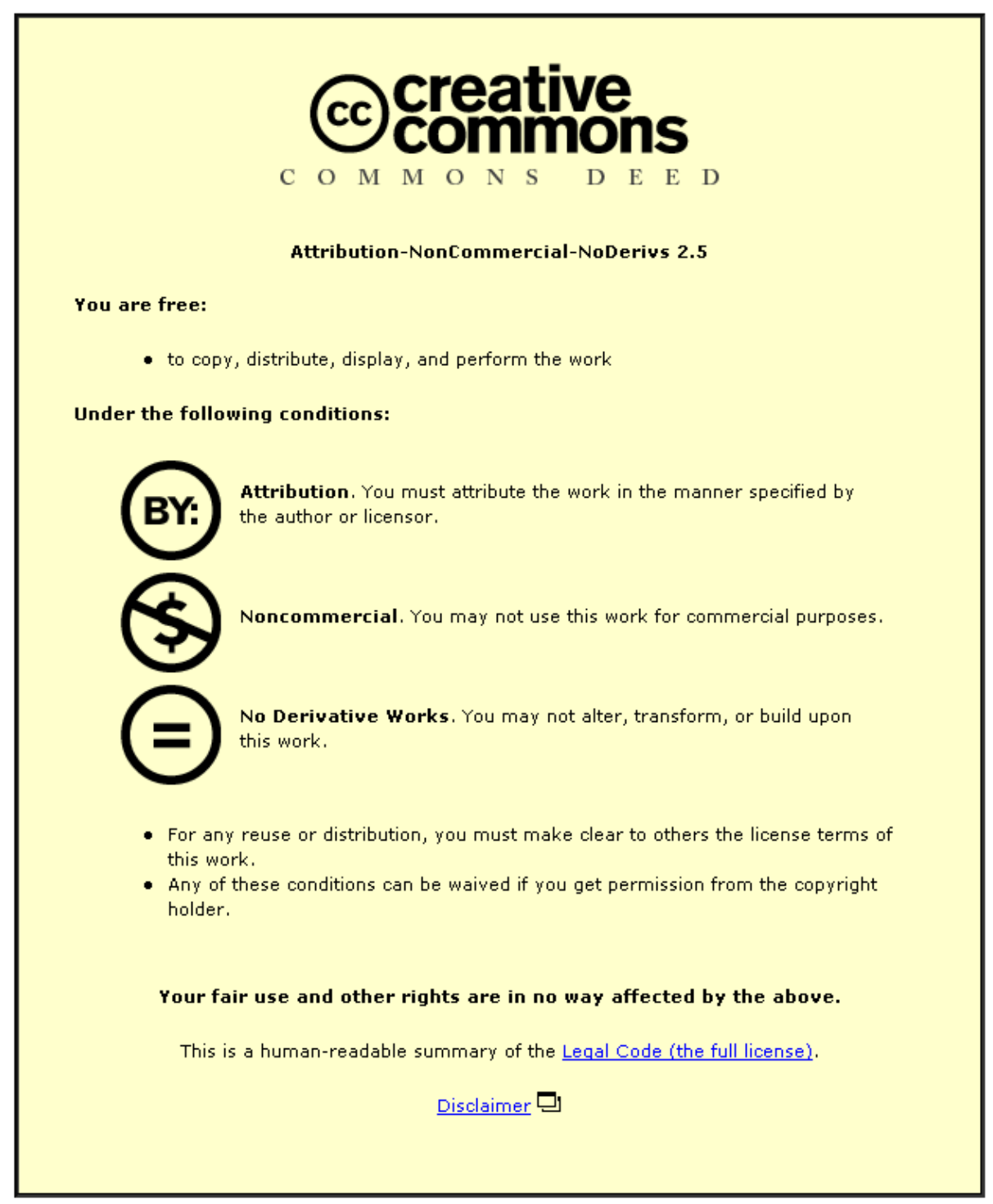

For the full text of this licence, please go to: http://creativecommons.org/licenses/by-nc-nd/2.5/ 


\title{
Production of food-grade multiple emulsions with high encapsulation yield using oscillating membrane emulsification
}

\author{
Goran T. Vladisavljevic ${ }^{1,2 *}$, Bing Wang ${ }^{1,3}$, Marijana M. Dragosavac ${ }^{1}$ and Richard G.
} Holdich $^{1}$

\author{
${ }^{1}$ Chemical Engineering Department, Loughborough University, Loughborough LE11 3TU, \\ UK. \\ ${ }^{2}$ Laboratory of Chemical Dynamics, Vinča Institute of Nuclear Sciences, PO Box 522, 11001 \\ Belgrade, Serbia. \\ ${ }^{3}$ Technology Centre, Zhejiang Xinan Chemical Industrial Group Co., Ltd, 7 Shihuiba, \\ Gongshu District, Hangzhou, 310014 Zhejiang, P.R.China. \\ *: To whom correspondence should be addressed: g.vladisavljevic@lboro.ac.uk \\ Tel: + 44 (0) 1509 222518; Fax: + 44 (0) 1509223923
}

\begin{abstract}
Food-grade water-in-oil-in-water (W/O/W) multiple emulsions with a volume median diameter of outer droplets of 50-210 $\mu \mathrm{m}$ were produced by injecting a water-in-oil (W/O) emulsion at the flux of $30 \mathrm{~L} \mathrm{~m}^{-2} \mathrm{~h}^{-1}$ through a $10-\mu \mathrm{m}$ pore electroplated nickel membrane oscillating at $10-90 \mathrm{~Hz}$ frequency and $0.1-5 \mathrm{~mm}$ amplitude in $2 \mathrm{wt} \%$ aqueous Tween ${ }^{\circledR} 20$ (polyoxyethylene sorbitan monolaurate) solution. The oil phase in the primary W/O emulsion was $5 \mathrm{wt} \%$ PGPR (polyglycerol polyricinoleate) dissolved in sunflower oil and the content of water phase in the W/O emulsion was 30 vol\%. The size of outer droplets was precisely controlled by the amplitude and frequency of membrane oscillation. Only 3-5 \% of the inner droplets with a mean diameter of $0.54 \mu \mathrm{m}$ were released into the outer aqueous phase during membrane emulsification. A sustained release of $200 \mathrm{ppm}$ copper (II) loaded in the inner aqueous phase was investigated over 7 days. 95\% of $\mathrm{Cu}(\mathrm{II})$ initially present in the inner water phase was released in the first 2 days from $56-\mu m$ diameter multiple emulsion droplets and less than $15 \%$ of $\mathrm{Cu}(\mathrm{II})$ was released over the same interval from $122 \mu \mathrm{m}$ droplets. The release rate of $\mathrm{Cu}(\mathrm{II})$ decreased with increasing the size of outer droplets and followed nonzero-order kinetics with a release exponent of $0.3-0.5$. The prepared multiple emulsions can
\end{abstract}


be used for controlled release of hydrophilic actives in the pharmaceutical, food, and cosmetic industry.

\section{Key words}

Multiple emulsion $\bullet$ Oscillating membrane $\bullet$ Sustained release $\bullet$ Membrane emulsification $\bullet$ Microencapsulation.

\section{Introduction}

A water-in-oil-in-water (W/O/W) multiple emulsion is a three-liquid-phase system consisting of aqueous phase droplets dispersed within larger oil droplets, which are themselves dispersed in another aqueous phase [1]. Due to their hierarchical organisation and multicompartmental structure, multiple emulsions may find useful applications in various fields, such as particle synthesis [2], microencapsulation [3], sustained release [4], separation processes [5], and formulation of low-fat food products [6]. W/O/W emulsions are usually prepared via a two-step emulsification process using two sets of surfactants. First, W/O emulsion is formed under high-shear conditions in the presence of hydrophobic surfactant(s) dissolved in the oil phase, whereas the second step is carried out in the presence of hydrophilic surfactant(s) dissolved in the outer aqueous phase and under low shear stress to minimise the release of inner water droplets. Conventional emulsification devices usually lead to highly polydisperse outer droplets and/or low yields of inner droplets.

Multiple emulsions with monodispersed outer droplets and $100 \%$ yield of inner droplets can be prepared using microfluidic strategies, for example using a T-junction or hydrodynamic flow focusing $[7,8]$. Furthermore, microfluidic approaches enable control over the internal structure of multiple emulsion and can be used for single-step generation of core-shell droplets [9], high-order multiple emulsion droplets (triple, quadruple, and quintuple) containing multiple concentric shells [10], multiple emulsion droplets with a controlled number of inner droplets [11], and multiple emulsion droplets containing two distinct types of inner droplets [12]. However, microfluidic channels suffer from wetting and clogging problems and the flow rates of the dispersed phase are very low, typically $0.01-10 \mathrm{ml} \mathrm{h}^{-1}$. Droplet throughput can be improved by injecting a dispersed phase through silicon microchannel arrays consisting of hundreds of thousands of parallel microchannels [13, 14]. 
W/O/W emulsions were also prepared by passing a W/O/W pre-emulsion through a microporous glass membrane multiple times $[15,16]$ or injecting a W/O emulsion through membrane into an agitating [17-18] or recirculating [19] continuous phase liquid. Membrane emulsification devices and processes have been recently reviewed by several authors [20, 21, 8]. Although shear stress on the membrane surface in these methods is very low, the droplets can be disrupted during prolonged recirculation or agitation. Breakage of droplets in the product stream can be minimised by delivering the continuous phase in pulsed cross flow [22] or using rotating membrane [23], which eliminates the need for recirculating or agitating the product.

Pawlik and Norton [24] prepared food grade W/O/W emulsions using three different techniques: SPG cross-flow membrane, SPG rotating membrane and high-shear mixer. The emulsions prepared using the rotating membrane released only small amounts of sodium chloride from the inner droplets (up to 1.2\%) during the emulsification process compared to the high-shear mixer (up to $2.8 \%$ for 10 min mixing) and the cross-flow membrane (up to $7.5 \%$ for $45 \mathrm{~min}$ recirculation). The amount of salt released during storage was also found to depend on the emulsification technique (8-20\% for the cross-flow membrane, $13 \%$ for the high-shear mixer and 8\% for the rotating membrane). Schuch et al. [25] compared production of $\mathrm{W} / \mathrm{O} / \mathrm{W}$ emulsions in rotor-stator devices (colloid mill and tooth rim dispersing machine), high pressure homogenizers (standard and modified) and high-shear rotating membrane device with stainless steel wire mesh membrane. The encapsulation efficiency of inner droplets, measured by differential scanning calorimetry (DSC), was found to predominantly depend on the size of the outer oil drops: the bigger the oil drops in $\mathrm{W} / \mathrm{O} / \mathrm{W}$ emulsions, the higher the measured encapsulation efficiency. Multiple emulsions with comparable oil drop sizes produced with different devices showed very similar encapsulation efficiency [25].

In this work, we have used a novel membrane emulsification strategy for production of $\mathrm{W} / \mathrm{O} / \mathrm{W}$ emulsion based on injection of W/O emulsion through oscillating nickel membrane. In this process, shear stress is generated on the membrane/product interface, but not in the bulk of the product stream, which preserves the integrity of multiple emulsion droplets after formation and leads to high yields of inner droplets. Another advantage of oscillating membrane over stirred and cross-flow emulsification systems is that it can easily be scaled up because the droplet size is independent on the system geometry. 


\section{Experimental}

\subsection{Materials}

The oil phase in $\mathrm{W}_{1} / \mathrm{O} / \mathrm{W}_{2}$ emulsions was $5 \mathrm{wt} \%$ PGPR (polyglycerol polyricinoleate, Stepan UK Ltd, Stalybridge) dissolved in refined sunflower oil with a density and viscosity at $25{ }^{\circ} \mathrm{C}$ of $915 \mathrm{~kg} \mathrm{~m}^{-3}$ and $51 \mathrm{mPa} \cdot \mathrm{s}$, respectively. The inner aqueous phase $\left(\mathrm{W}_{1}\right)$ was $0.9 \mathrm{wt} \% \mathrm{NaCl}$ solution, which was isotonic with human blood serum and the content of inner aqueous phase in the oil phase was 30 vol\%. The outer aqueous phase $\left(\mathrm{W}_{2}\right)$ was $2 \mathrm{wt} \%$ Tween $^{\circledR} 20$ (polyoxyethylene sorbitan monolaurate, Fluka, UK) containing $0.9 \mathrm{wt} \% \mathrm{NaCl}$ to counteract the osmotic pressure in the inner droplets and provide osmotic equilibrium. The density and viscosity of the outer aqueous phase at $25^{\circ} \mathrm{C}$ were $1000 \mathrm{~kg} \mathrm{~m}^{-3}$ and $1.01 \mathrm{mPa} \cdot \mathrm{s}$, respectively and the interfacial tension at the interface between the outer aqueous phase and $\mathrm{W} / \mathrm{O}$ emulsion was $0.83 \mathrm{mN} \mathrm{m}^{-1}$. In the controlled release experiments, $\mathrm{NaCl}$ from the inner water phase was replaced by 2000 ppm $\mathrm{CuSO}_{4}$ (Fisher Scientific, UK). Cu(II) in the form of copper sulphate (Fisher Scientific, UK). Cu(II) was used as a marker, because $\mathrm{Cu}(\mathrm{II})$ concentration in aqueous phase was measured by atomic adsorption spectroscopy down to parts per billion, so that even the smallest changes in the released $\mathrm{Cu}(\mathrm{II})$ could be detected.

\subsection{Oscillating membrane emulsification rig}

Oscillating membrane emulsification system (Micropore Technology Ltd, Hatton, England) used in this work is shown in Figure 1. The membrane used was a nickel membrane containing spatially regular hexagonal array of cylindrical pores with a diameter of $d_{p}=$ $10 \mu \mathrm{m}$ and interpore distance of $\mathrm{L}=200 \mu \mathrm{m}$, fabricated by galvanic deposition of nickel onto a microfabricated template. The membrane porosity was $0.2 \%$, as calculated from the equation [26]:

$\varepsilon=\frac{\pi}{2 \sqrt{3}}\left(\frac{d_{p}}{L}\right)^{2}$

The membrane was in the form of a vertical hollow tube with a conical stainless steel bottom, used to reduce turbulence during oscillation. The outside diameter and height of the 
membrane tube was 15 and $57 \mathrm{~mm}$, respectively. At the top of the membrane tube there was a 1/8 inch BSP fitting to enable the tube to be attached to the inlet manifold. The oscillation signal was generated by an audio generator (Rapid Electronics), which fed a power amplifier driving the electro-mechanical oscillator on which the inlet manifold was mounted. The frequency and amplitude of the oscillation were determined by a PCB Piezotronics analogue accelerometer (M352C65) attached to the inlet manifold. The accelerometer was connected to a National Instruments analogue-to-digital converter (NI eDAQ-9172) interfaced to a LabView executable program, which was used to analyse the output signal from the accelerometer.

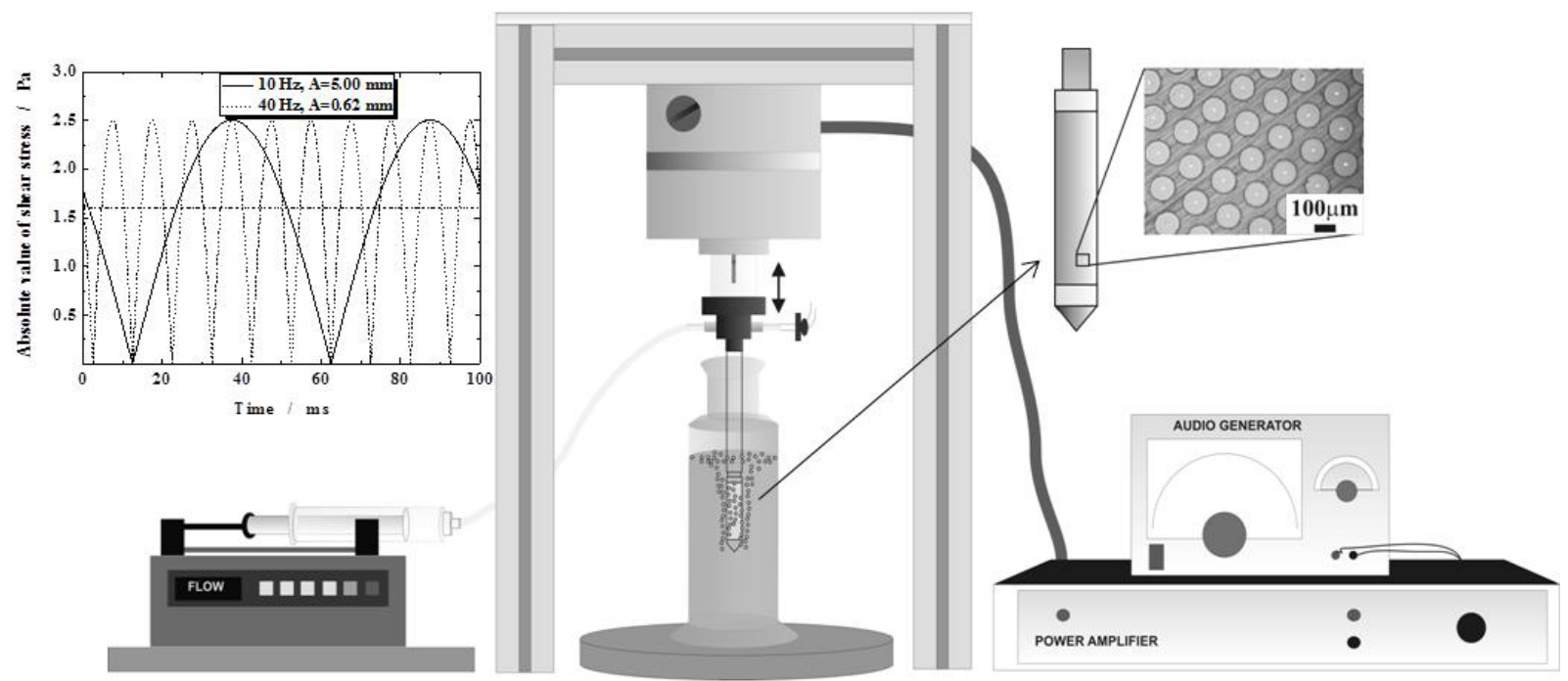

Figure 1. Schematic view of the experimental setup for oscillating membrane emulsification. A magnified detail at the top right corner is the membrane tube with optical micrograph of the membrane surface. The inset in the top left corner shows temporal variations of the shear stress on the membrane surface at 10 and $40 \mathrm{~Hz}$ and amplitude of 5.0 and $0.6 \mathrm{~mm}$, respectively over $100 \mathrm{~ms}$. The peak shear stress was $2.5 \mathrm{~Pa}$ in both cases.

\subsection{Procedure}

$\mathrm{W}_{1} / \mathrm{O} / \mathrm{W}_{2}$ emulsions were prepared by a two-step emulsification procedure. The primary $\left(\mathrm{W}_{1} / \mathrm{O}\right)$ emulsion was produced using a homogeniser (Ultra Turrax ${ }^{\circledR}$, model T25, IKA Works, USA) at 24,000 rpm for $5 \mathrm{~min}$, which resulted in the mean diameter of water droplets of 0.54 $\mu \mathrm{m}$. If the pore diameter of the membrane is equal to or smaller than the diameter of the water particles, the water particles will be rejected by the membrane so that it will be impossible to obtain a W/O/W emulsion [27]. In this case, the maximum size of the water 
droplets was one order of magnitude smaller than the pore size. The $\mathrm{W}_{1} / \mathrm{O}$ emulsion was then injected through the membrane (pre-soaked in a wetting agent for at least $30 \mathrm{~min}$ to increase the hydrophilicity of the surface) using a Harvard Apparatus model 11 Plus syringe pump. The transmembrane flux in all experiments was $30 \mathrm{~L} \mathrm{~m}^{-2} \mathrm{~h}^{-1}$ and the final concentration of $\mathrm{W}_{1} / \mathrm{O}$ emulsion in $\mathrm{W}_{1} / \mathrm{O} / \mathrm{W}_{2}$ emulsion was 5 vol\%. Once the desired amount of the $\mathrm{W}_{1} / \mathrm{O}$ emulsion had passed through the membrane both the pump and the oscillator were switched off and the droplets were collected and analysed. The membrane was cleaned with $8 \mathrm{M}$ $\mathrm{NaOH}$ in an ultrasonic bath for 5 min followed by treatment in $10 \mathrm{vol} \% \mathrm{HCl}$ solution for 5 min. To evaluate the drop-size distribution and droplet diameter, a laser diffraction particle size analyzer (Malvern Mastersizer, Model S) was used. For each emulsion, three separate samples and measurements were performed and the arithmetic mean of these was reported. The mean particle size was expressed as the volume median diameter $d(v, 0.5)$, which is the diameter corresponding to 50 vol\% on the cumulative distribution curve. The relative span of a drop size distribution was used to express the degree of drop size uniformity: span $=[d(v, 0.9)-d(v, 0.1)] / d(v, 0.5)$. The micrograph of membrane surface was taken using a Leitz Ergolux optical microscope, whereas the micrographs of emulsion droplets were taken using Medline Scientific microscope in the reflected light mode. The entrapment efficiency and the release rate of copper (II) were measured using disposable centrifugal ultrafiltration (UF) unit (Vivaspin 6, Sartorius AG, Goettingen, Germany) to separate the droplets from the continuous phase and then Atomic Absorbance Spectrometry (using Spectra AA-200 Varian, UK) to analyse the filtrate. Centrifugal separation was performed at $1300 \mathrm{rpm}$ for $40 \mathrm{~min}$ using a Heraeus Labofuge 400R centrifuge (Thermo Scientific, Germany) and the polyethersulfone membrane used to separate the droplets from the continuous phase had a mean pore size of $0.2 \mu \mathrm{m}$. The operating parameters used in the range of $\mathrm{Cu}(\mathrm{II})$ concentration of 0.03-10 ppm were: wavelength $=324.7 \mathrm{~nm}$, slit width $=0.2 \mathrm{~nm}$ and fuel $=$ acetylene.

The entrapment efficiency (EE) of $\mathrm{Cu}(\mathrm{II})$ was defined as a mass of $\mathrm{Cu}(\mathrm{II})$ entrapped in multiple emulsion droplets immediately after the emulsification process (at $t=0$ ) divided by the total mass of $\mathrm{Cu}(\mathrm{II})$ added to the inner water phase, $M_{\mathrm{i}}$ :

$$
E E=\frac{\text { mass of } \mathrm{Cu}(\mathrm{II}) \text { added }- \text { mass of } \mathrm{Cu}(\mathrm{II}) \text { released at } \mathrm{t}=0}{\text { mass of } \mathrm{Cu}(\mathrm{II}) \text { added }}=\frac{M_{i}-M_{0}}{M_{i}}
$$


where $M_{0}$ is the mass of $\mathrm{Cu}(\mathrm{II})$ released at $\mathrm{t}=0$. The mass of $\mathrm{Cu}(\mathrm{II})$ added to the inner water phase is given by:

$M_{i}=C_{i} \phi_{\text {wo }} \phi_{\text {wow }} V_{\text {wow }}$

where $C_{i}$ is the initial concentration of $\mathrm{Cu}(\mathrm{II})$ in the inner water phase, $V_{\text {wow }}$ is the volume of the $\mathrm{W}_{1} / \mathrm{O} / \mathrm{W}_{2}$ emulsion produced, $\phi_{w o}$ is the volume fraction of the water phase in the $\mathrm{W}_{1} / \mathrm{O}$ emulsion, and $\phi_{\text {wow }}$ is the volume fraction of the $\mathrm{W}_{1} / \mathrm{O}$ emulsion in the $\mathrm{W}_{1} / \mathrm{O} / \mathrm{W}_{2}$ emulsion. Neglecting the change in the volume of the outer water phase as a result of expulsion of the inner droplets, the mass of $\mathrm{Cu}(\mathrm{II})$ released at $\mathrm{t}=0$ is given by:

$M_{0}=C_{0} V_{\text {wow }}\left(1-\phi_{\text {wow }}\right)$

where $C_{0}$ is the concentration of $\mathrm{Cu}(\mathrm{II})$ in the outer water phase at $\mathrm{t}=0$. The substitution of Equations (3) and (4) into Equation (2) gives:

$E E=1-\frac{C_{0}}{C_{i}} \frac{1-\phi_{\text {wow }}}{\phi_{\text {wow }} \phi_{\text {wo }}}$

In this work, $C_{i}=2000 \mathrm{ppm}, \phi_{w o}=0.3$, and $\phi_{w o w}=0.05$. The release profile of $\mathrm{Cu}(\mathrm{II})$ from the inner droplets was monitored by measuring the concentration of $\mathrm{Cu}$ (II) in the permeate after incubation of the emulsion at room temperature for a specific time period and centrifugal separation. The maximum concentration of $\mathrm{Cu}(\mathrm{II})$ in the permeate corresponding to infinitely long release time was $C_{\infty}=31.6 \mathrm{ppm}$, calculated from Equation (5) as $C_{0}$ value for $E E=0$.

\section{Results and Discussion}

\subsection{Influence of parameters of membrane oscillation on droplet size}

Figures 2 and 3 show the influence of amplitude and frequency of membrane oscillation on the size of multiple emulsion droplets produced. As shown in Figure 2, the size of outer droplets was varied from 50 to $212 \mu \mathrm{m}$ by using different combinations of amplitude and frequency. Therefore, the droplet size can be controlled without interrupting the process and 
replacing the membrane. Although the droplets were not monodispersed, a relative span of the particle size distribution of $0.36-0.56$ was comparable to what was achieved in cross-flow SPG membrane emulsification [28, 29]. The ratio of the droplet size to the pore size of 5-21 is greater than 3-4, found when using Shirasu Porous Glass (SPG) membrane in the dripping regime $[19,28]$. It can be explained by non-spherical tortuous pores of SPG membrane [2930], causing a droplet to strongly deform before detachment and providing additional droplet detaching force based on the system's tendency to lower its interfacial free energy [31-32]. Another reason for high droplet-to-pore size ratio observed for nickel membrane is a high velocity of the dispersed phase in the pores due to low membrane porosity, which leads to dripping-to-jetting transition at the lower transmembrane flux than for SPG membrane of the same pore size. The membrane used in this work had a porosity of only $0.2 \%$, while SPG membrane has the porosity between 50 and $60 \%$ [30]. 


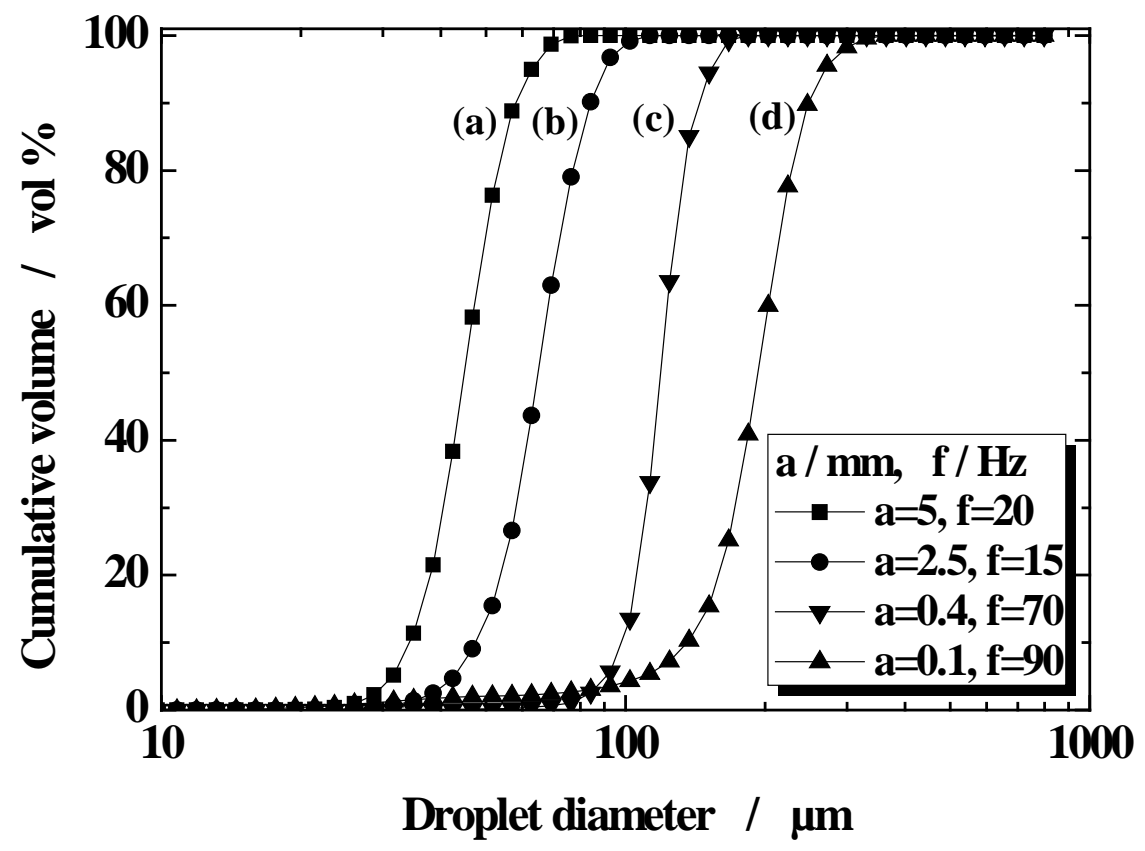

Figure 2. Optical micrographs and particle size distributions of multiple emulsions produced in this work. The operating parameters are so chosen to show the ability of oscillating membrane with the same pore size to produce droplets of widely different sizes: (a) a=5 mm, $\mathrm{f}=20 \mathrm{~Hz}$; (b) $\mathrm{a}=2.5 \mathrm{~mm}, \mathrm{f}=15 \mathrm{~Hz}$; (c) $\mathrm{a}=0.4 \mathrm{~mm}, \mathrm{f}=70 \mathrm{~Hz}$; (d) a=0.1 mm, f=90 Hz.

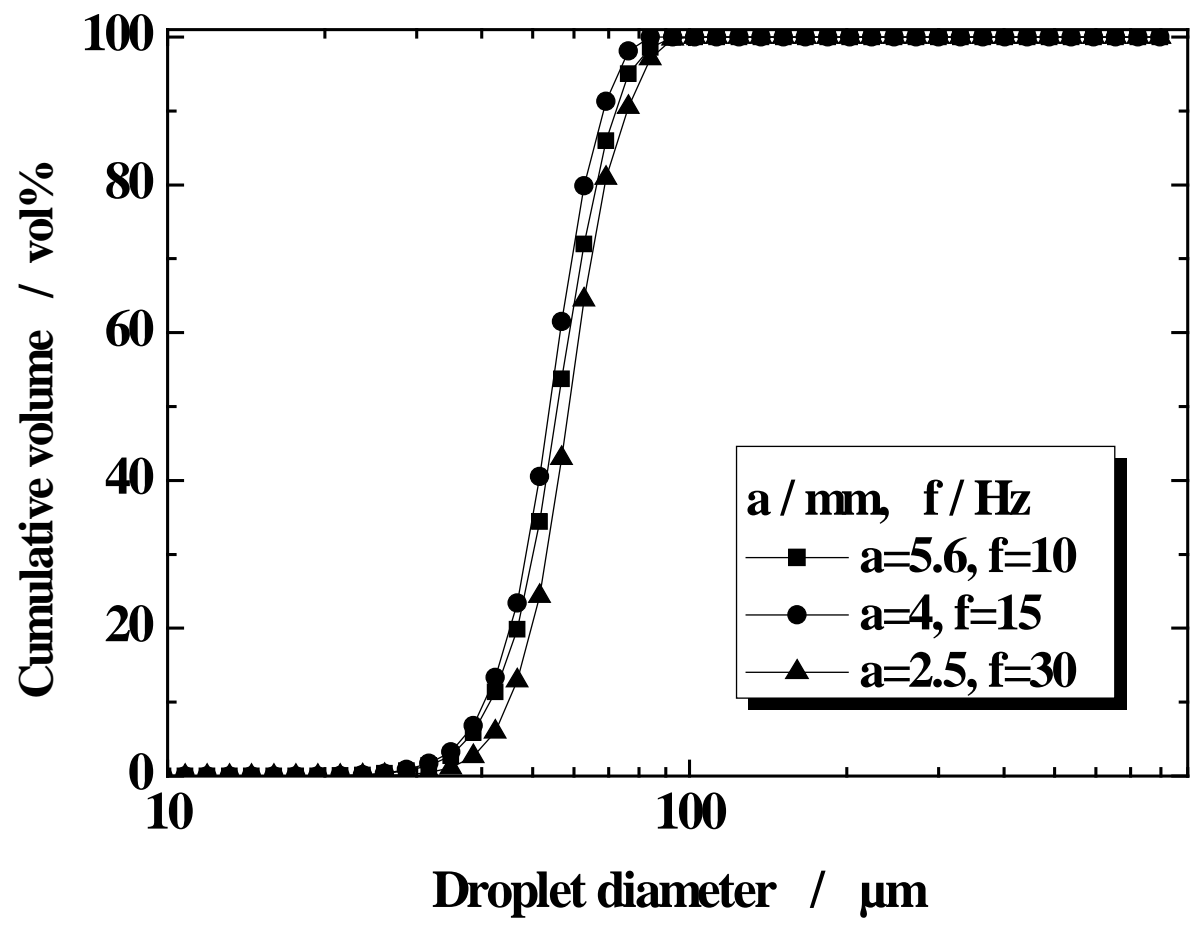

Figure 3. Particle size distributions of multiple emulsions with similar droplet sizes prepared using different combinations of frequency and amplitude. 
In oscillating membrane emulsification, there are two independent parameters affecting shear stress on the membrane surface: frequency and amplitude of the membrane oscillation. In order to produce emulsions with the same particle size distribution, the higher amplitude must be offset by the lower frequency and vice versa (Figure 3). Therefore, the droplet size in oscillating membrane emulsification is not determined by individual values of the frequency or amplitude but a combination of both values. Oscillating membrane system provides a higher degree of control over the droplet size than in a cross-flow, stirred cell or rotating membrane system, where there is only one hydrodynamic parameter that can be used to adjust shear stress (cross flow velocity, stirrer speed or membrane rotation speed).

In the dripping regime the diameter $x$ of outer droplets is determined by the balance between the shear force pulling a droplet tangentially along the membrane surface and the interfacial tension force resisting that motion. In equilibrium [33]:

$x=\frac{\sqrt{18 \tau_{\max }^{2} r_{p}^{2}+2 \sqrt{81 \tau_{\max }^{4} r_{p}^{4}+4 r_{p}^{2} \tau_{\max }^{2} \gamma^{2}}}}{3 \tau_{\max }}$

where $r_{p}$ is the pore radius, $\tau_{\max }$ is the peak shear stress on the membrane surface and $\gamma$ is the interfacial tension between the outer aqueous phase and the oil phase. Eq. (6) is valid for the zero inertial force of the dispersed phase, i.e. for low velocities of the dispersed phase in the pores. The peak shear stress is the maximum value of the shear stress given by [34]:

$$
\tau_{\max }=(2 \pi)^{3 / 2}\left(\mu_{a q} \rho_{a q}\right)^{1 / 2} a f^{3 / 2}
$$

where $a$ and $f$ is the amplitude and frequency and $\mu_{a q}$ and $\rho_{a q}$ is the viscosity and density of the outer aqueous phase. Eq. (7) indicates that the same $\tau_{\max }$ value can be obtained for any pair of $a$ and $f$ values that satisfy the condition: $a_{2} / a_{1}=\left(f_{1} / f_{2}\right)^{3 / 2}$. Therefore, the effect of higher frequency can be counterbalanced by decreasing amplitude, as shown in Figure 3.

Figure 4 shows the volume median diameter as a function of the peak shear stress on the membrane surface for $\mathrm{O} / \mathrm{W}$ and $\mathrm{W} / \mathrm{O} / \mathrm{W}$ emulsions prepared at different frequencies ranging from 10 to $40 \mathrm{~Hz}$. The lines in Figure 4 are model curves constructed using Eqs. (6) and (7). A droplet should experience at least one peak shear event during formation on the membrane 
surface for the model to be applicable. Since there are $2 / f$ peak shear events per oscillation, the droplet formation time should be greater than 50 and 12.5 ms at $f=10$ and $40 \mathrm{~Hz}$, respectively. The droplet formation time depends on the percentage of active pores. The higher the percentage of active pores, the smaller the velocity of the dispersed phase in the pores and the longer the droplet formation time becomes. The percentage of active pores can only be determined by microscopic observation of the membrane surface [30] and therefore, it was unknown in this work. For $f=40 \mathrm{~Hz}$ and $d(v, 0.5)=50 \mu \mathrm{m}$ (the smallest droplet size in Figure 4), the droplet formation time was estimated to be more than $20 \mathrm{~ms}$ for the percentage of active pores of $10 \%$ and $12.5 \mathrm{~ms}$ for the percentage of active pores of $6 \%$.

As shown in Figure 4, the droplet size decreased with increasing the peak shear stress, which is a type of behaviour observed in all membrane emulsification systems (cross flow, pulsed cross flow, stirred cell, and spinning membrane). It can be seen that the droplets with different diameters were produced at the same frequency, which was due to different peak shear stresses imposed on a droplet by using different amplitudes. The droplet size reached a minimum limiting value at the shear stress of about $5 \mathrm{~Pa}$ indicating that the peak shear stress does not need to be above $5 \mathrm{~Pa}$. The model predicted the size of O/W droplets very well, but underestimated the size of $\mathrm{W} / \mathrm{O} / \mathrm{W}$ droplets, which could be explained by partial wetting of the membrane surface, due to presence of PGPR and inner water phase in the oil phase. As a result of membrane wetting, the dispersed phase was not held in the pore areas, but spread over the larger area around a pore. However, the span of the particle size distribution was similar to that for $\mathrm{O} / \mathrm{W}$ emulsions produced in the same oscillating membrane device [34]. 


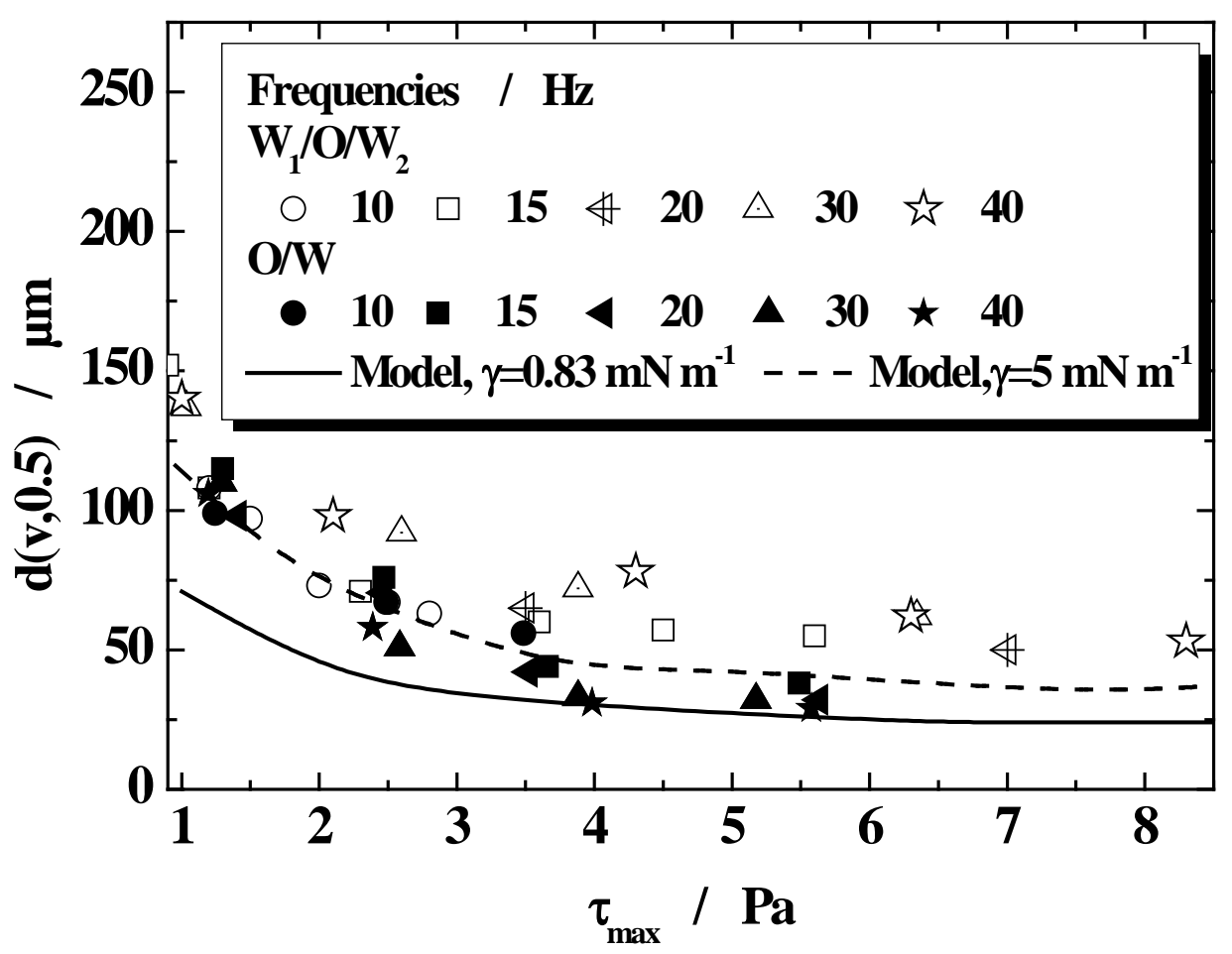

Figure 4. The volume median diameter as a function of the peak shear stress at the membrane surface for $\mathrm{O} / \mathrm{W}$ and $\mathrm{W} / \mathrm{O} / \mathrm{W}$ emulsions prepared at different frequencies. The solid and dashed line is a model curve for $\mathrm{O} / \mathrm{W}$ and $\mathrm{W} / \mathrm{O} / \mathrm{W}$ emulsions, respectively, constructed using Eqs. (1) and (2). For O/W emulsion $\gamma=5 \mathrm{mN} \mathrm{m}^{-1}$ and for multiple emulsion $\gamma=0.83 \mathrm{mN} \mathrm{m}^{-1}$.

\subsection{Controlled release from the prepared multiple emulsions}

The entrapment efficiency of $\mathrm{Cu}(\mathrm{II})$ under different experimental conditions was calculated using Equation (5) and expressed as a percentage. As shown in Figure 5, the entrapment efficiency of $\mathrm{Cu}(\mathrm{II})$ ranged from 95 to $97 \%$ and increased with increasing the Sauter mean diameter of outer droplets in the range from 56 to $122 \mu \mathrm{m}$. The release of copper (II) during membrane emulsification was probably due to the release of inner water droplets, because emulsification time was only several minutes. The maximum shear stress at the membrane surface led to the smallest multiple emulsion droplets and caused the maximum release of the marker, which corresponds well with previous findings obtained in the Dispersion Cell [17] and rotating membrane emulsification [25]. 


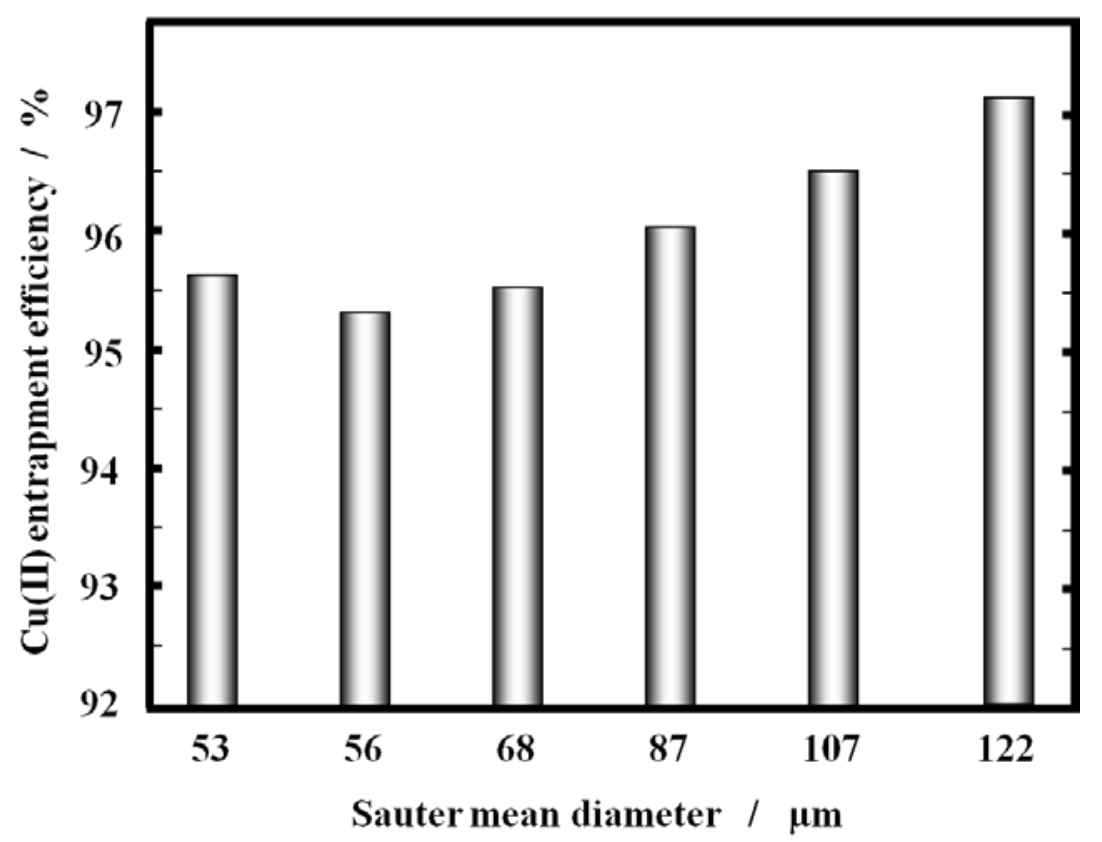

Figure 5. The entrapment efficiency of $\mathrm{Cu}(\mathrm{II})$ in the prepared multiple emulsions as a function of Sauter mean diameter of outer droplets.

The relative amount of $\mathrm{Cu}(\mathrm{II})$ released from the inner droplets at time $t$ was calculated using the following equation:

$R=\frac{M_{t}-M_{0}}{M_{i}-M_{0}}=\frac{C_{t}-C_{0}}{C_{\infty}-C_{0}}=\frac{C_{t}-C_{0}}{C_{i}\left[\phi_{\text {wow }} \phi_{\text {wo }} /\left(1-\phi_{\text {wow }}\right)\right]-C_{0}}$

where $M_{t}$ is the mass of $\mathrm{Cu}(\mathrm{II})$ released at time $\mathrm{t}$, and $C_{t}$ and $C_{\infty}$ is the concentration of $\mathrm{Cu}(\mathrm{II})$ present in the outer water phase after the incubation period of $t$ and $\infty$, respectively. Figure 6 shows the percentage of copper (II) released from the oil droplets $(R \times 100)$ during stationary storage at room temperature as a function of the Sauter mean diameter of the outer droplets. Although phase separation (creaming) observed during storage, the oil droplets did not coalesce. The release of $\mathrm{Cu}(\mathrm{II})$ followed non-zero-order kinetics with the release rate decreasing with time according to the Korsmeyer-Peppas model [35]: $C_{t} / C_{\infty}=K t^{n}$, where $K$ is the release rate constant and $n$ is the release exponent. To find $n$ value, the portion of the release curve where $C_{t} / C_{\infty}<0.6$ should only be used. Due to limited number of data points that satisfy this condition, the release exponent could not be determined very accurately. The values of $n$ were found to range from 0.3 to 0.5 for different curves in Figure 6. It should be noted that $n=0.5$ corresponds to Fickian diffusion mechanism. The release rate was higher for 
smaller outer droplets, due to higher interfacial area per unit volume, as would be expected for the transfer by molecular diffusion. The maximum amount of $\mathrm{Cu}$ (II) released into the outer aqueous phase was 95.3-96.0 \% and was achieved after 2-6 days for the emulsions with $d_{3,2}=53-68 \mu \mathrm{m}$. The remaining $4-4.7 \%$ of $\mathrm{Cu}(\mathrm{II})$ was captured within the droplets and could not be released, probably because the recovery yield of C(II) from the aqueous phase was less than $100 \%$. The recovery yield was defined by Regan and Mulvihill [36] as the concentration of marker in the aqueous phase recovered from an emulsion that has been separated into a cream layer and an aqueous phase by centrifugation relative to the concentration of marker present in (or added to) the outer aqueous phase after emulsion preparation. In addition, $\mathrm{Cu}$ (II) could react with free fatty acids from sunflower oil to form copper salts of fatty acids (soaps). The copper oleate was synthesised by reacting $\mathrm{Cu}$ (II) with sodium oleate in the mixture of ethanol, distilled water and hexane at $70{ }^{\circ} \mathrm{C}$ [37]. Although in this work emulsions were stored at room temperature and sunflower oil differs from the above mentioned solvent mixture, the formation of copper soups cannot be fully excluded. Figure 6 shows that the emulsion with the biggest droplets $\left(d_{2,3}=122 \mu \mathrm{m}\right)$ prepared by imposing the minimum shear stress on the membrane surface released the lowest amount of $\mathrm{Cu}(\mathrm{II})$, only $22 \%$ after one week.

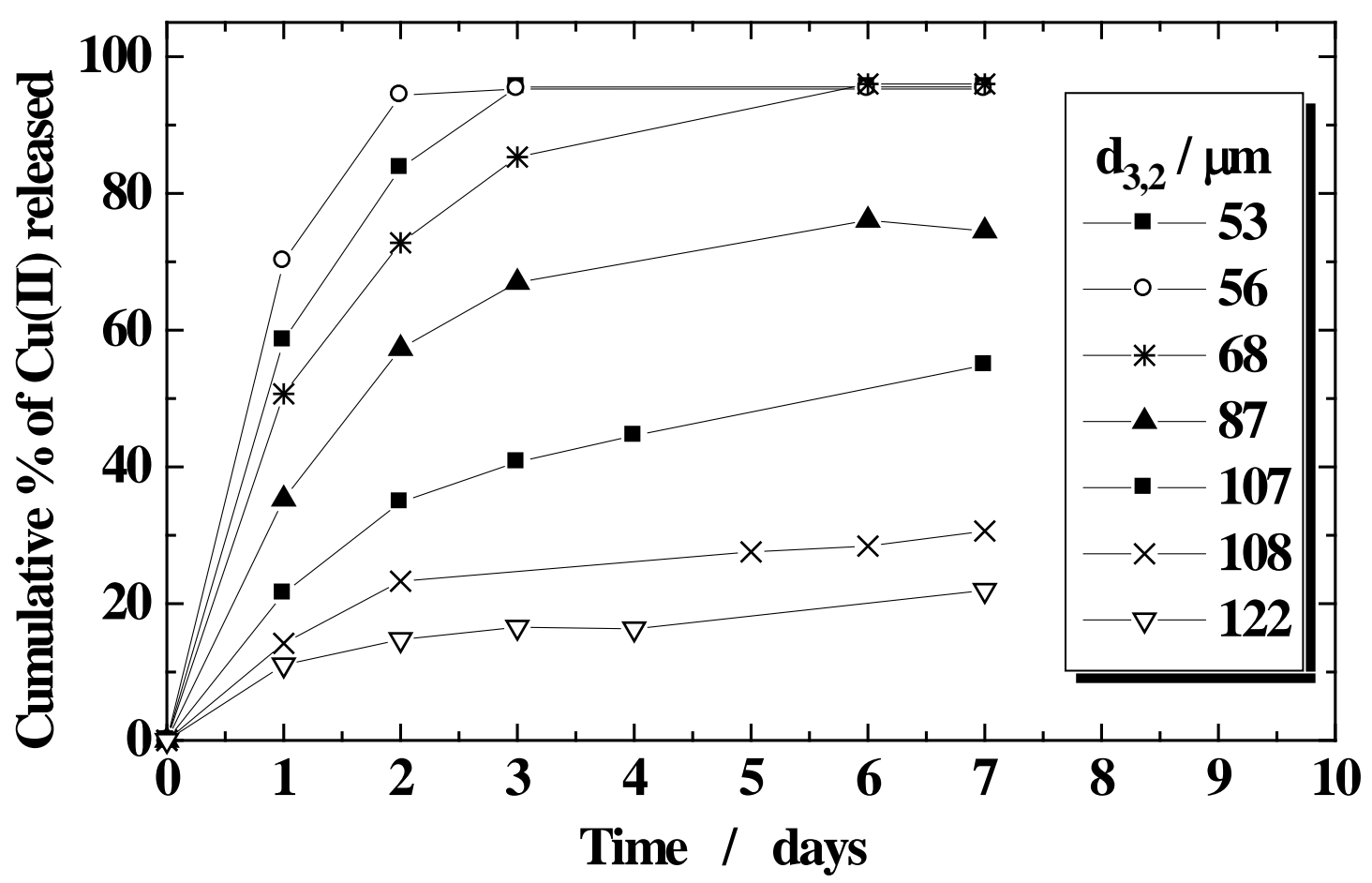

Figure 6. The amount of copper(II) released from multiple emulsions during incubation at room temperature as a function of the Sauter mean diameter $d_{3,2}$ of outer droplets. 


\subsection{Comparison of different emulsification methods}

In Figure 7, particle size distribution curves and optical micrographs of multiple emulsions were compared for the following three emulsification methods: (a) Ultra Turrax ${ }^{\circledR}$ at $2000 \mathrm{rpm}$ for $60 \mathrm{~s}$, (b) magnetic stirrer at $1760 \mathrm{rpm}$ for $300 \mathrm{~s}$, and (c) oscillating membrane at $a=0.4$ mm and $f=70 \mathrm{~Hz}$. The multiple emulsion produced by Ultra Turrax ${ }^{\circledR}$ had a bimodal distribution with the first peek between 0.1 and $1 \mu \mathrm{m}$ and the second peak between 10 and 30 $\mu \mathrm{m}$. Small micron-sized droplets and large $10-\mu \mathrm{m}$ droplets are noticeable in the micrograph in the upper left corner of Figure 7. The droplets produced by magnetic stirrer and oscillating membrane had very similar mean droplet size (111 and $122 \mu \mathrm{m})$, but the oscillating membrane system produced more uniform droplets then magnetic stirrer. The encapsulation efficiency, $\mathrm{EE}$, for the emulsion with $\mathrm{d}_{3,2}=111 \mu \mathrm{m}$ prepared using magnetic stirrer was $96 \%$, as compared to the EE of just over $97 \%$ for the emulsions with $d_{3,2}=122 \mu \mathrm{m}$ prepared using oscillating membrane at $0.4 \mathrm{~mm}$ amplitude and $70 \mathrm{~Hz}$ frequency. These results confirm previous findings that $\mathrm{W} / \mathrm{O} / \mathrm{W}$ emulsions with comparable oil drop sizes produced with different emulsification devices give approximately the same EE [25]. The EE was $70 \%$ for the homogenisation process performed with Ultra Turrax ${ }^{\circledR}$ at $11,000 \mathrm{rpm}$ for $300 \mathrm{~s}$, but the EE was improved to $93 \%$ when the mixing time was decreased to $10 \mathrm{~s}$ at $11,000 \mathrm{rpm}$. 

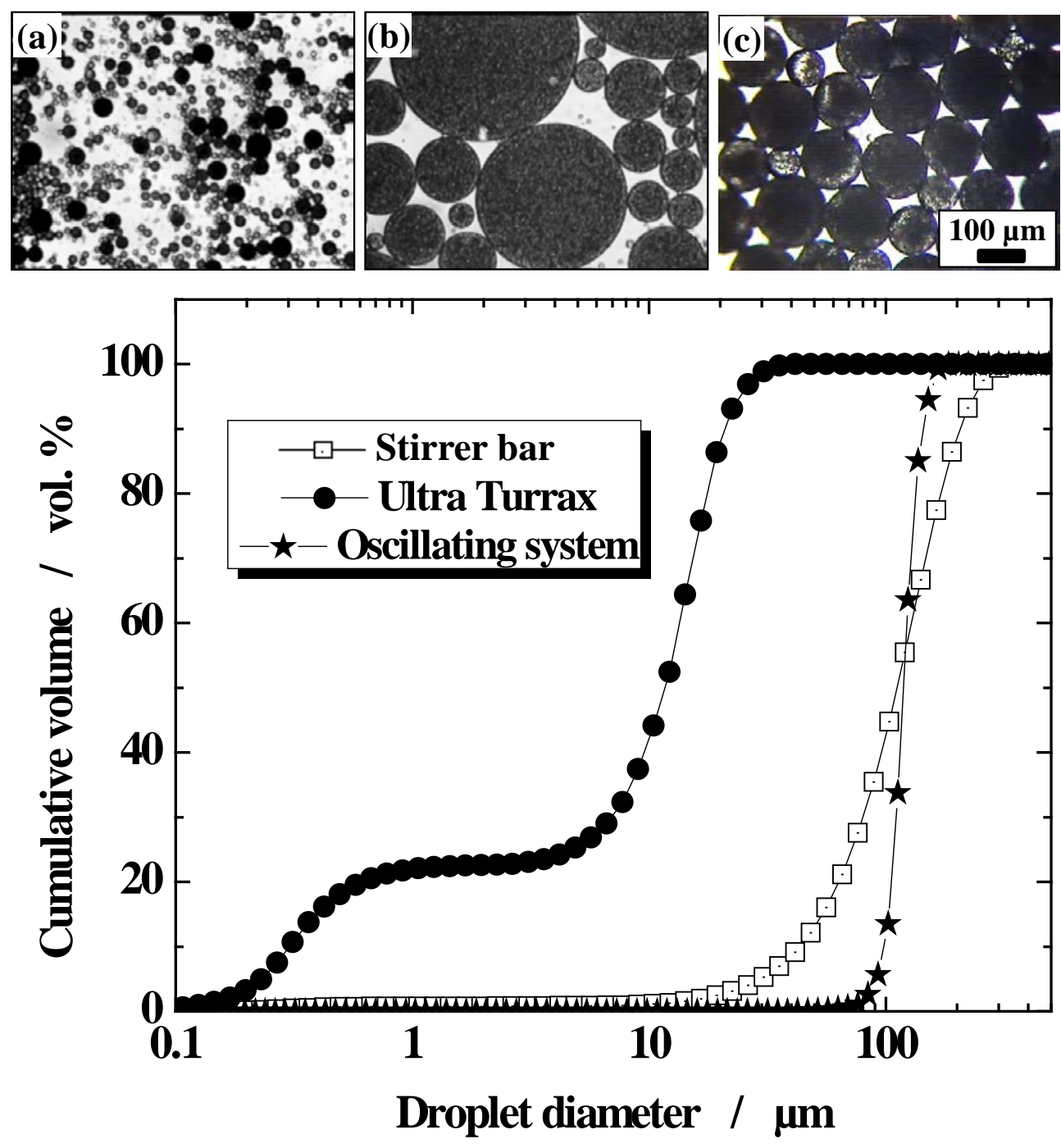

Figure 7. Optical micrograph and particle size distribution of multiple emulsions produced using three different emulsification methods: (a) Ultra Turrax ${ }^{\circledR}$ at $2000 \mathrm{rpm}$ for $60 \mathrm{~s}$; (b) Magnetic stirrer at $1760 \mathrm{rpm}$ for $300 \mathrm{~s}$; (c) Oscillating membrane at a=0.4 mm and f $=70 \mathrm{~Hz}$. The same scale bar applies to micrographs (a), (b), and (c).

\section{Conclusions}

Multiple emulsions with high entrapment efficiency of hydrophilic marker (copper salt) of 95-97\% and narrow particle size distribution ( $\operatorname{span}=0.36-0.56$ ) were produced using oscillating membrane emulsification. High encapsulation efficiency of the marker was attributed to low shear stresses imposed in the bulk of the continuous phase during membrane oscillations. Multiple emulsions with the biggest outer droplets released the smallest amount of marker (less than 3\%) from the inner droplets during the emulsification process. The size of outer droplets was precisely controlled by the two membrane oscillation parameters: 
frequency and amplitude that can be changed independently and used to calculate the peak shear stress on the membrane surface, a single parameter that determines the droplet size. The droplet size was found to decrease with increasing the peak shear stress, irrespectively of the individual values of frequency or amplitude. The force balance model predicted well the size of single emulsion droplets, but underestimated the size of multiple emulsion droplets. The release of copper (II) from inner water droplets was characterised by an initial burst, which can be attributed to the release of inner droplets into the outer aqueous phase during membrane emulsification, followed by a sustained release during storage as a result of molecular diffusion through the oil phase. The rate of copper release decreased with increasing the droplet size and followed non-zero-order kinetics with a release exponent ranging between 0.3 and 0.5 .

\section{References}

[1] N. Garti, C. Bisperink, Double emulsions: Progress and applications, Curr. Opin. Colloid Interface Sci. 3 (1998) 657-667.

[2] H.Y. Koo, S.T. Chang, W.S. Choi, J.H. Park, D.Y. Kim, O.D. Velev, Emulsion-based synthesis of reversibly swellable, magnetic nanoparticle-embedded polymer microcapsules, Chem. Mater. 18 (2006) 3308-3313.

[3] M.E. Rodríduez-Huezo, R. Pedroza-Islas, L.A. Prado-Barragán, C.I. Beristain, E.J. Vernon-Carter, Microencapsulation by spray drying of multiple emulsions containing carotenoids, J. Food Sci. 69 (2004) 351-359.

[4] N. Jager-Lezer, I. Terrisse, F. Bruneau, S. Tokgoz, L. Ferreira, D. Clausse, M. Seiller, J.L. Grossiord, Influence of lipophilic surfactant on the release kinetics of watersoluble molecules entrapped in a W/O/W multiple emulsion, J. Controlled Release 45 (1997) 1-13.

[5] J. Draxler, W. Fürst, R. Marr, Separation of metal species by emulsion liquid membranes, J. Membr. Sci. 38 (1988) 281-293.

[6] J. Surh, G.T. Vladisavljević, S. Mun, D.J. McClements, Preparation and characterization of water/oil and water/oil/water emulsions containing biopolymergelled water droplets, J. Agric. Food Chem. 55 (2007) 175-184. 
[7] G.T. Vladisavljević, N. Khalid, M.A. Neves, T. Kuroiwa, M. Nakajima, K. Uemura, S. Ichikawa, I. Kobayashi, Industrial lab on a chip: design, applications and scale up for drug discovery and delivery, Adv. Drug Delivery Rev. 65 (2013) 1626-1663.

[8] G.T. Vladisavljević, I. Kobayashi, M. Nakajima, Production of uniform droplets using membrane, microchannel and microfluidic emulsification devices, Microfluid. Nanofluid. 13 (2012) 151-178.

[9] G.T. Vladisavljević, H.C. Shum, D.A. Weitz, Control over the shell thickness of core/shell drops in three-phase glass capillary devices, Prog. Colloid Polym. Sci. 139 (2012) 115-118.

[10] A.R. Abate, D.A. Weitz, High-order multiple emulsions formed in poly(dimethylsiloxane) microfluidics, Small 5 (2009) 2030-2032.

[11] L.Y. Chu, A.S. Utada, R.K. Shah, J.W. Kim, D.A. Weitz, Controllable monodisperse multiple emulsions, Angew. Chem. Int. Ed. 46 (2007) 8970-8974.

[12] B.J. Sun, H.C. Shum, C. Holtze, D.A. Weitz, Microfluidic melt emulsification for encapsulation and release of actives, ACS Appl. Mater. Interfaces 2 (2010) 34113416.

[13] I. Kobayashi, X. Lou, S. Mukataka, M. Nakajima, Preparation of monodisperse waterin-oil-in-water emulsions using microfluidization and straight-through microchannel emulsification, J. Am. Oil Chem. Soc. 82 (2005) 65-71.

[14] I. Kobayashi, M.A. Neves, Y. Wada, K. Uemura, M. Nakajima, Large microchannel emulsification device for mass producing uniformly sized droplets on a liter per hour scale, Green Process. Sci. 1 (2012) 353-362.

[15] G.T. Vladisavljević, M. Shimizu, T. Nakashima, Preparation of monodisperse multiple emulsions at high production rates by multi-stage premix membrane emulsification, J. Membr. Sci. 244 (2004) 97-106.

[16] G.T. Vladisavljević, M. Shimizu, T. Nakashima, Production of multiple emulsions for drug delivery systems by repeated SPG membrane homogenization: Influence of mean pore size, interfacial tension and continuous phase viscosity, J. Membr. Sci. 284 (2006) 373-383.

[17] M.M. Dragosavac, R.G. Holdich, G.T. Vladisavljević, M. Sovilj, Stirred cell membrane emulsification for multiple emulsions containing unrefined pumpkin seed oil with uniform droplet size, J. Membr. Sci. 392-393 (2012) 122-129. 
[18] M.A. Suárez, G. Gutiérrez, J. Coca, C. Pazos, Geometric parameters influencing production of $\mathrm{O} / \mathrm{W}$ emulsions using flat metallic membranes and scale-up, J. Membr. Sci. 430 (2013) 140-149.

[19] G.T. Vladisavljević, H. Schubert, Influence of process parameters on droplet size distribution in SPG membrane emulsification and stability of prepared emulsion droplets, J. Membr. Sci. 225 (2003) 15-23.

[20] F. Spyropoulos, D. Lloyd, R.D. Hancocks, A.K. Pawlik, Advances in membrane emulsification. Part A: Recent developments in processing aspects and microstructural design approaches, J. Food Sci. Eng. 94 (2014) 613-627.

[21] A. Nazir, K. Schroën, R. Boom, Premix emulsification: A review, J. Membr. Sci. 362 (2010) 1-11.

[22] R.G. Holdich, M. Dragosavac, G.T. Vladisavljević, E. Piacentini, Continuous membrane emulsification with pulsed (oscillatory) flow, Ind. Eng. Chem. Res. 52 (2013) 507-515.

[23] G.T. Vladisavljević, R.A. Williams, Manufacture of large uniform droplets using rotating membrane emulsification, J. Colloid Interface Sci. 299 (2006) 369-402.

[24] A.K. Pawlik, I.T. Norton, Encapsulation stability of duplex emulsions prepared with SPG cross-flow membrane, SPG rotating membrane and rotor-stator techniques-A comparison, J. Membr. Sci. 415-416 (2012) 459-468.

[25] A. Schuch, J. Wrenger, H.P. Schuchmann, Production of W/O/W double emulsions. Part II: Influence of emulsification device on release of water by coalescence, Colloids Surf., A, http://dx.doi.org/10.1016/j.colsurfa.2013.11.044.

[26] M.M. Dragosavac, M.N. Sovilj, S.R. Kosvintsev, R.G. Holdich, G.T. Vladisavljević, Controlled production of oil-in-water emulsions containing unrefined pumpkin seed oil using stirred cell membrane emulsification, J. Membr. Sci. 322 (2008) 178-188.

[27] Y. Mine, M. Shimizu, T. Nakashima, Preparation and stabilization of simple and multiple emulsions using a microporous glass membrane, Colloids Surf., B 6 (1996) 261-268.

[28] G.T. Vladisavljević, H. Schubert, Preparation and analysis of oil-in-water emulsions with a narrow droplet size distribution using Shirasu-porous-glass (SPG) membranes, Desalination, 144 (2002) 167-172. 
[29] G.T. Vladisavljević, M. Shimizu, T. Nakashima, Permeability of hydrophilic and hydrophobic Shirasu-porous-glass (SPG) membranes to pure liquids and its microstructure, J. Membr. Sci. 250 (2005) 69-77.

[30] G.T. Vladisavljević, I. Kobayashi, M. Nakajima, R.A. Williams, M. Shimizu, T. Nakashima, Shirasu Porous Glass membrane emulsification: Characterisation of membrane structure by high resolution x-ray microtomography and microscopic observation of droplet formation in real time, J. Membr. Sci. 302 (2007) 243-253.

[31] S. Sugiura, M. Nakajima, S. Iwamoto, M. Seki, Interfacial tension driven monodispersed droplet formation from microfabricated channel array, Langmuir 17 (2001) 5562-5566.

[32] M. Rayner, G. Trägårdh, C. Trägårdh, The impact of mass transfer and interfacial expansion rate on droplet size in membrane emulsification processes, Colloids Surf., A 266 (2005) 1-17.

[33] E. Egidi, G. Gasparini, R.G. Holdich, G.T. Vladisavljević, S.R. Kosvintsev, Membrane emulsification using membranes of regular pore spacing: Droplet size and uniformity in the presence of surface shear, J. Membr. Sci. 323 (2008) 414-420.

[34] R.G. Holdich, M.M. Dragosavac, G.T. Vladisavljević, S.R. Kosvintsev, Membrane emulsification with oscillating and stationary membranes, Ind. Eng. Chem. Res. 49 (2010) 3810-3817.

[35] R.W. Korsmeyer, R. Gurny, E. Doelker, P. Buri, N.A. Peppas, Mechanisms of solute release from porous hydrophilic polymers, Int. J. Pharm. 15 (1983) 25-35.

[36] J. O’ Regan, D.M. Mulvihill, Water soluble inner aqueous phase markers as indicators of the encapsulation properties of water-in-oil-in-water emulsions stabilized with sodium caseinate, Food Hydrocolloids 23 (2009) 2339-2345.

[37] J.J. Wang, J.S. Hu, Y.G. Guo, L.J. Wan, Wurtzite $\mathrm{Cu}_{2} \mathrm{ZnSnSe}_{4}$ nanocrystals for highperformance organic-inorganic hybrid photodetectors, NPG Asia Mater. 4 (2012) e2. 